\title{
Correction to: Impaired coronary blood flow may be related to elevated homocysteine levels in patients with metabolic syndrome
}

\author{
Yusuf I. Alihanoglu • Bekir S. Yildiz · Emin E. Özcan · Ismail D. Kilic · Deniz S. Kuru · Ozgur Taskoylu • \\ Halil Tanriverdi · Havane A. Kaftan · Harun Evrengul
}

Published online: 7 May 2018

(C) Springer-Verlag GmbH Austria, part of Springer Nature 2018

\section{Correction to:}

Wien Klin Wochenschr 2015

https://doi.org/10.1007/s00508-015-0854-z

The original version of this article unfortunately contained a mistake. The first names of Dr. Ismail Dogu Kilic were interchanged.

The online version of the original article can be found under https://doi.org/10.1007/s00508-015-0854-z.

Y. I. Alihanoglu, MD $(\bowtie) \cdot$ B. S. Yildiz, MD · I. D. Kilic, MD •

H. Tanriverdi, MD · H. A. Kaftan, MD · H. Evrengul, MD

Medical Faculty, Department of Cardiology, Pamukkale

University, Denizli, Turkey

aliizyu@mynet.com

E. E. Özcan, MD

Medical Faculty, Department of Cardiology, Sifa University,

Denizli, Turkey

D. S. Kuru, MD

Department of Cardiology, Referans Private Hospital, Aydın, Turkey

O. Taskoylu, MD

Department of Cardiology, ERPA Private Hospital, Denizli, Turkey 